\title{
DETERMINATION THE CONCENTRATION OF SOME METALS IN IMPORTED CANNED FOOD AND CHICKEN STOCK
}

\author{
AL-Rajhi, M.A. \\ Department of Physics, Al Imam Mohammad Ibn Saud Islamic University, \\ College of Science, P.O. Box 90950, Riyadh 11642, Kingdom of Saudi Arabia
}

Received 2014-03-4; Revised 2014-03-24; Accepted 2014-04-09

\begin{abstract}
This study was carried out to determine the level of same selected metals namely $\mathrm{Cd}, \mathrm{Cr}, \mathrm{Cu}, \mathrm{Fe}, \mathrm{K}, \mathrm{Mg}$, $\mathrm{Mn}, \mathrm{Ni}, \mathrm{Pb}, \mathrm{Zn}, \mathrm{As}, \mathrm{Se}, \mathrm{Al}$ and $\mathrm{V}$ in some imported canned foods and chicken stock purchased from the local market in Riyadh, Saudi Arabia. The measurements were performed using inductively coupled plasma-optical emission Spectrometer (SPECTRO) analytical instruments. The result showed that the average concentration of the elements was 0.0007 for $\mathrm{Cu}, 0.0197$ for $\mathrm{Fe}, 0.0029$ for $\mathrm{Mn}, 0.0018$ for $\mathrm{Ni}$, 0.0120 for $\mathrm{Zn}$ and 0.0005 for $\mathrm{Cr}, 0.001$ for $\mathrm{Cd}, 0.0137$ for Al, 0.0079 for AS and 0.0167 for Se. In comparison the concentration of heavy metals and essential metals in the current investigation with World Health Organization and Food and Agriculture Organization WHO/FAO legal limits. The average concentration of all heavy metals and essential elements were much lower than the reference limits. Based on the obtained results it can be concluded that the imported canned foods and chicken stock are free of heavy metals contamination.
\end{abstract}

Keyword: Chicken Stock, Canned Food, Essential Metals, Heavy Metals and ICP-OPS

\section{INTRODUCTION}

Some metals play an important role in the effective operation of biological systems and essential to human health ( $\mathrm{Se}, \mathrm{Mn}, \mathrm{Cu}, \mathrm{Ca}, \mathrm{Fe}, \mathrm{Zn}, \mathrm{Cr}$ ), though they're probably harmful if consumed in considerable quantities (Mohammed et al., 2011). Heavy Metals create a major contribution to environmental contamination due to human activities like mining, smelting, power transmission, intensive agriculture or heavy metal contamination affects the biosphere in several places worldwide (Aliu et al., 2013). There are some heavy metals could also be harmful to health like $\mathrm{As}, \mathrm{Pb}, \mathrm{Cd}$ and Hg haven't any identified helpful biological operation and long exposure could also be unhealthful even at low doses. Heavy metals are possible environmental pollutants with the ability of having human health problems if present in excess in the food we consume. They are given special interest in all over the world because of their poisonous effects even at even in low concentrations (Das, 1990). Though some individuals exposed to venomous elements, particularly in the workplace, for most people the main source of exposure to venomous elements is through the food (Leblanc et al., 2000). Food consumption had been specified as major route for human vulnerability to venomous metals, compared with different ways in which of exposure like inhalation and skin contact. US Environmental Protection Agency (US EPA), Joint FAO/WHO Expert Committee on Food Additives (JECFA) and Institute of Medicine of the National Academies (IOM) have given tips on the intake of trace by human beings. The IOM of the National Academies suggested the recommended the suitable quantity and also the the maximum allowable limit for some major elements (IOM, 2002; 2003). It is necessary to measure the levels of heavy metals in food and to report on possible contamination that would pose a threat to human health.. Several cases of human illness, disorders, breakdowns and deformation of organs as a result of metal toxicity have been reported (Järup, 2003). The level of heavy metals in foodstuffs have been 
reported around the world by (Wu Leung and Butrum, 1972; Jorherm and Sundstroem, 1993; Pennington et al., 2005; Hussein and Bruggeman, 1997). This study discusses the evaluation of heavy in some imported canned foods and chicken stock in light of international standards allowable limit set by WHO and FAO.

\section{MATERIALS AND METHODS}

\subsection{Study Area}

Riyadh is the capital city of the Kingdom of Saudi Arabia with an area of about $1554 \mathrm{~km}^{2}$. It is located centrally in the Najd region with a population that is expected to reach over 5.2 million in 2007, (Fig. 1). Riyadh is the major part of Riyadh Province. It is situated in the centre of the Arabian Peninsula on latitude $34^{\circ}-38^{\circ}$ north and longitude $46^{\circ}-43^{\circ}$ east $600 \mathrm{~m}$ above sea level.

\subsection{Samples Collection and Preparation}

A total of 21 different type of imported canned foods (tuna, sardine and chicken stock) samples were collected from the supermarkets around the city of Riyadh and transported in plastic bags to the environmental research laboratory at AL imam Mohammad Ibn Saud Islamic University for elemental analysis. Samples were dried and after drying, samples were grained into a fine powder using a ceramic mill and stored in polyethylene bags until used for acid digestion.

\subsection{Chemicals and Reagents}

All the standard stock solutions of heavy metals were certified reference materials that were purchased from agilent technologies (USA). $\mathrm{HNO}_{3}$ and $\mathrm{H}_{2} \mathrm{O}_{2}$ were heavy metal analysis grade and purchased from Wako Chemical Co. (USA). Reagent water, toluene and acetone were of analytical reagent grade and purchased from J.T. Baker (USA).

\subsection{Acid Digestion of Samples}

About $10 \mathrm{~mL}$, high purity $\mathrm{HNO}_{3}$ and $2 \mathrm{~mL}$ hydrogen peroxide were added to the beaker containing $2 \mathrm{~g}$ of dry $2 \mathrm{~g}$ of dry samples were placed in the fume cupboard for two days for digestion. The mixture was then digested at $80^{\circ} \mathrm{C}$ till the transparent solution was achieved. After cooling, the digested samples were filtered using Buchner funnels and the filtrate was diluted to $50 \mathrm{~mL}$ with distill water. The final solution were used for the elements analysis namely $\mathrm{Cd}, \mathrm{Cr}, \mathrm{Cu}, \mathrm{Fe}, \mathrm{K}, \mathrm{Mg}, \mathrm{Mn}, \mathrm{Ni}, \mathrm{Pb}, \mathrm{Zn}, \mathrm{As}, \mathrm{Se}$ and Al by ICP optical emission spectrometer.

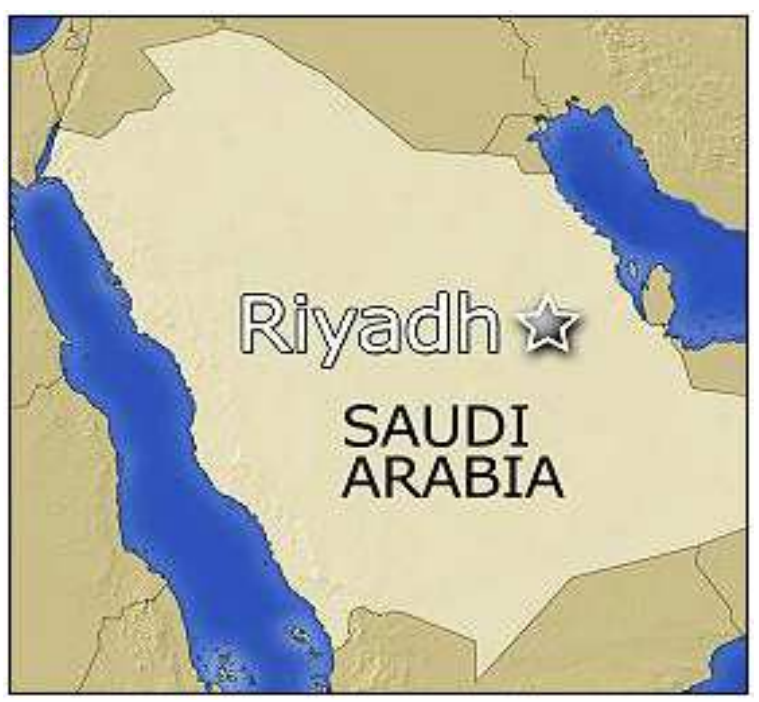

Fig. 1. Kingdom of Saudi Arabia map showing the study area

\subsection{Spectrometric Analysis}

The measurements were performed using a GENESIS ICP optical emission spectrometer (SPECTRO Analytical Instruments, Kleve, Germany) with axial plasma observation. The instrument includes a Paschen-Runge mount spectrometer, constructed employing the Optimized Rowland Circle Alignment (ORCA) technique. It consists of two hollow section cast shells, designed for direct thermal stabilization and small volume. 15 pre-aligned linear CCD detectors are installed on the outside of the optics body, which allow fast, simultaneous spectrum capture of the wavelength range between 175 and $777 \mathrm{~nm}$. For UV access $(<200$ $\mathrm{nm})$, the optical system purged with argon. The purge rate during normal operation is $0.5 \mathrm{~L} \mathrm{~min}^{-1}$. To enable method transfer between individual instruments, Intelligent Calibration Logic (ICAL) was used to normalize the wavelength and the intensity scale of the optical system to a reference optic ("optic master"). Stability of the forward power in the case of rapidly changing sample loads was achieved through use of an air-cooled ICP-generator, based on a free running 27.12 $\mathrm{MHz}$ system. All ICP operating parameters were software controlled. The ICP-OES instrument was initialized and allowed to achieve thermal equilibrium over $30 \mathrm{~min}$. Multi-element Solution Standards obtained from Agilen technology were used to calibrate and quantitate sample results. The Lower Detection Limit of the system (LDL) was calculated and found to be $0.00001 \mathrm{mg} \mathrm{kg}^{-1}$ on the average. ICP-OES 
determinations of elements concentration were performed using the emission lines 228.802, 267.716, 324.752, 238.204, 766.490, 285.213, 259.372, 231.604, $220.353,213.857,189.641,196.090$ and $384.401 \lambda$ (nm) for the elements $\mathrm{Cd}, \mathrm{Cr}, \mathrm{Cu}, \mathrm{Fe}, \mathrm{K}, \mathrm{Mg}, \mathrm{Mn}, \mathrm{Ni}$, $\mathrm{Pb}, \mathrm{Zn}, \mathrm{As}$, Sea nd $\mathrm{Al}$ respectively.

\section{RESULTS}

The concentration of the elements $\mathrm{Cu}, \mathrm{Zn}, \mathrm{Fe}, \mathrm{Cr}, \mathrm{Mn}$ and $\mathrm{Ni}$ are presented in Table $\mathbf{1}$ and concentration of $\mathrm{Cd}$, $\mathrm{Al}, \mathrm{Pb}, \mathrm{As}$ and $\mathrm{Se}$ are presented in Table 2. The trace elements $\mathrm{Cu}, \mathrm{Fe}, \mathrm{Mn}, \mathrm{Ni}, \mathrm{Zn}$ and $\mathrm{Cr}$ concentrations ranged from $0.0001-0.0017,0.0065-0.0488,0.0005$ $0.0084, \quad 0.0003-0.0060, \quad 0.0025-0.0308$ and $0.0008-$ $0.0047 \mathrm{mg} \mathrm{kg}^{-1}$ with an average value of $0.0007,0.0197$, $0.0029,0.0018,0.0120$ and $0.0005 \mathrm{mg} \mathrm{kg}^{-1}$ respectively. The concentration of Se varied from 0.001-0.0278 with an average value of $0.0167 \mathrm{mg} \mathrm{kg}^{-1}$. The results of the analyses indicate that concentration of $\mathrm{Al}, \mathrm{Pb}$ and $\mathrm{As}$ varied from 0.007-0.0442, 0.0004-0.009 and 0.0011$0.0124 \mathrm{mg} \mathrm{kg}^{-1}$, on the average $0.0137-0.0044$ and $0.0079 \mathrm{mg} \mathrm{kg}^{-1}$ respectively.

Table 1. $\mathrm{Cu}, \mathrm{Zn}, \mathrm{Fe}, \mathrm{Se}, \mathrm{Mn}$ and Ni concentration $(\mathrm{mg} / \mathrm{kg})$ and statistical summary of imported canned foods

\begin{tabular}{lllllll}
\hline Samples No & $\mathrm{Cu}$ & $\mathrm{Fe}$ & $\mathrm{Mn}$ & $\mathrm{Ni}$ & $\mathrm{Zn}$ & $\mathrm{Cr}$ \\
\hline 1 & 0.0017 & 0.0110 & 0.0005 & 0.0020 & 0.0025 & 0.0029 \\
2 & 0.0002 & 0.0081 & 0.0039 & 0.0003 & 0.0123 & 0.0005 \\
3 & 0.0003 & 0.0093 & 0.0084 & 0.0006 & 0.0077 & 0.0015 \\
4 & 0.0004 & 0.0239 & 0.0037 & 0.0008 & 0.0071 & 0.0014 \\
5 & 0.0004 & 0.0149 & 0.0034 & 0.0014 & 0.0103 & 0.0022 \\
6 & 0.0005 & 0.0397 & 0.0014 & 0.0056 & 0.0113 & 0.0081 \\
7 & 0.0003 & 0.0065 & 0.0026 & 0.0011 & 0.0094 & 0.0010 \\
8 & 0.0007 & 0.0190 & 0.0020 & 0.0014 & 0.0146 & 0.0023 \\
9 & 0.0008 & 0.0488 & 0.0014 & 0.0060 & 0.0113 & 0.0086 \\
10 & 0.0001 & 0.0081 & 0.0017 & 0.0006 & 0.0030 & 0.0010 \\
11 & 0.0016 & 0.0167 & 0.0024 & 0.0007 & 0.0308 & 0.0008 \\
12 & 0.0012 & 0.0400 & 0.0061 & 0.0021 & 0.0264 & 0.0043 \\
13 & 0.0017 & 0.0110 & 0.0005 & 0.0020 & 0.0025 & 0.0009 \\
Min & 0.0001 & 0.0065 & 0.0005 & 0.0003 & 0.0025 & 0.0008 \\
Max & 0.0017 & 0.0488 & 0.0084 & 0.0060 & 0.0308 & 0.0047 \\
Average & 0.0007 & 0.0197 & 0.0029 & 0.0018 & 0.0120 & 0.0005 \\
Std & 0.0005 & 0.0137 & 0.0021 & 0.0018 & 0.0077 & 0.0086 \\
\hline
\end{tabular}

Table 2. $\mathrm{Cd}, \mathrm{Al}, \mathrm{Pb}, \mathrm{Se}, \mathrm{As}$ and Se concentration $(\mathrm{mg} / \mathrm{kg}$ ) and statistical summary of imported canned foods

\begin{tabular}{llllll}
\hline Samples no. & Cd & $\mathrm{Al}$ & $\mathrm{Pb}$ & $\mathrm{As}$ & \\
\hline 1 & LDL & 0.0266 & 0.0004 & 0.0011 & $\mathrm{Se}$ \\
2 & LDL & LDL & LDL & LDL & 0.0031 \\
3 & LDL & 0.0170 & 0.0090 & 0.0115 & LDL \\
4 & LDL & 0.0442 & 0.0077 & 0.0258 \\
5 & LDL & 0.0143 & 0.0077 & 0.0110 & 0.0266 \\
6 & 0.001 & 0.0117 & 0.0017 & 0.0081 & 0.0170 \\
7 & 0.001 & 0.0070 & 0.0048 & 0.0039 & 0.0086 \\
8 & LDL & 0.0116 & 0.0040 & 0.0101 & 0.0193 \\
9 & LDL & 0.0085 & 0.0030 & 0.0091 & 0.0181 \\
10 & LDL & 0.0048 & 0.0051 & 0.0055 & 0.0131 \\
11 & LDL & 0.0113 & 0.0053 & 0.0092 & 0.0197 \\
12 & LDL & 0.0104 & 0.0029 & 0.0059 & 0.0135 \\
13 & 0.0010 & 0.0182 & 0.0074 & 0.0124 & 0.0278 \\
Min & 0.0010 & 0.0070 & 0.0004 & 0.0011 & 0.0011 \\
Max & 0.0010 & 0.0442 & 0.0090 & 0.0124 & 0.0278 \\
Average & 0.0010 & 0.0137 & 0.0044 & 0.0079 & 0.0167 \\
Std & 0.0001 & 0.0105 & 0.0027 & 0.0039 & 0.0085 \\
\hline
\end{tabular}




\section{DISCUSSION}

$\mathrm{Cd}, \mathrm{Cr}, \mathrm{Cu}, \mathrm{Fe}, \mathrm{K}, \mathrm{Mg}, \mathrm{Mn}, \mathrm{Ni}, \mathrm{Pb}, \mathrm{Zn}, \mathrm{As}$, Se nd Al were chosen as representative metals whose levels in the environment represent a reliable indicator of environmental contamination metals such as $\mathrm{Cu}, \mathrm{Fe}, \mathrm{K}, \mathrm{Mg}, \mathrm{Mn}, \mathrm{Ni}, \mathrm{Zn}$ and $\mathrm{Se}$ are essential metals since they play an important role in biological systems, whereas $\mathrm{Al}$ and $\mathrm{Pb}, \mathrm{Cd}$ and $\mathrm{As}$ are non-essential metals as they are toxic even in low concentration. The order of trace elements concentration in different type of canned foods obtined are $\mathrm{Fe}$ $\mathrm{Se}>\mathrm{Zn}>\mathrm{Mn}>\mathrm{Ni}>\mathrm{Cu}>\mathrm{Cr}$. The essential metals can also produce toxic effects when the metal intake is high concentration (Al-Khlaifat and Al-Khashman, 2007). According to the WHO recommendation, the daily intakes of the element of $\mathrm{Fe} \mathrm{Se}, \mathrm{Zn}, \mathrm{Mn}, \mathrm{Ni}, \mathrm{Cu}$ and $\mathrm{Cr}$ in the current study fall far below than the legal limit set by the WHO/FAO (Joint FAO/WHO, 2011). Up on comparing the average concentration of $\mathrm{Cu}, \mathrm{Zn}, \mathrm{Ni}$ in this survey with similar data reported in previous study in Saudi Arabia $2006 \mathrm{Cu}\left(0.27 \mathrm{mg} \mathrm{k}^{-1}\right), \mathrm{Cr}(0.3 \mathrm{mg}$ $\left.\mathrm{k}^{-1}\right)$, Ni (23 mg $\left.\mathrm{kg}^{-1}\right)$. It was found that the concentration of such elements in my study was lower than those that we compare.The average value for $\mathrm{Pb}$ obtained from the result were lower than the maximum level of $\mathrm{Pb} 0.5 \mathrm{mg} \mathrm{kg}$-1 permitted by (Joint FAO/WHO, 2011) worldwide data 0.59, 0.28, 0.35, 0.011 $\mathrm{mg} \mathrm{kg}^{-1}$ reported by (Tariq et al., 1993; Voegborlo et al., 1999; CIFA, 1992; Mani et al., 2012). Average value of As concentration reported in the current survey less than the legal limit adopted by the FAO/WHO.Cd was detected 3 samples out of 13, all within acceptable levels set by (Joint FAO/WHO, 2011) $0.5 \mathrm{mg} \mathrm{kg}$. Aluminum is not considered to be an essential element in humans. The aluminum average value fall far below the permissible daily intake $60 \mathrm{mg}$ day $^{-1}$ (FAO/WHO, 1989). The regression analysis has shown that significant correlation was noted between Se and As concentration as shown in (Fig. 2). On the other hand positive correlation was found between $\mathrm{As}$ and $\mathrm{Pb}$ (Fig. 3).

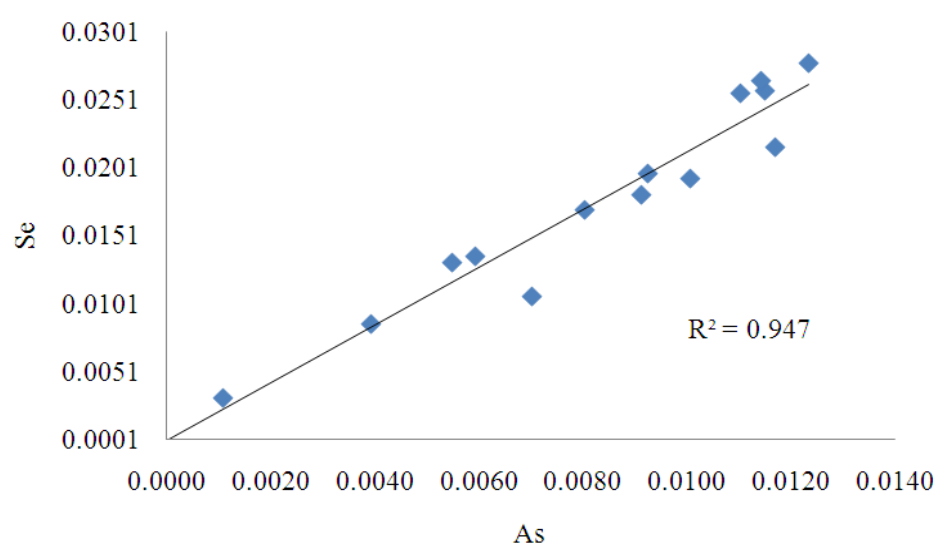

Fig. 2. Se concentration as funcation of As cconcentration

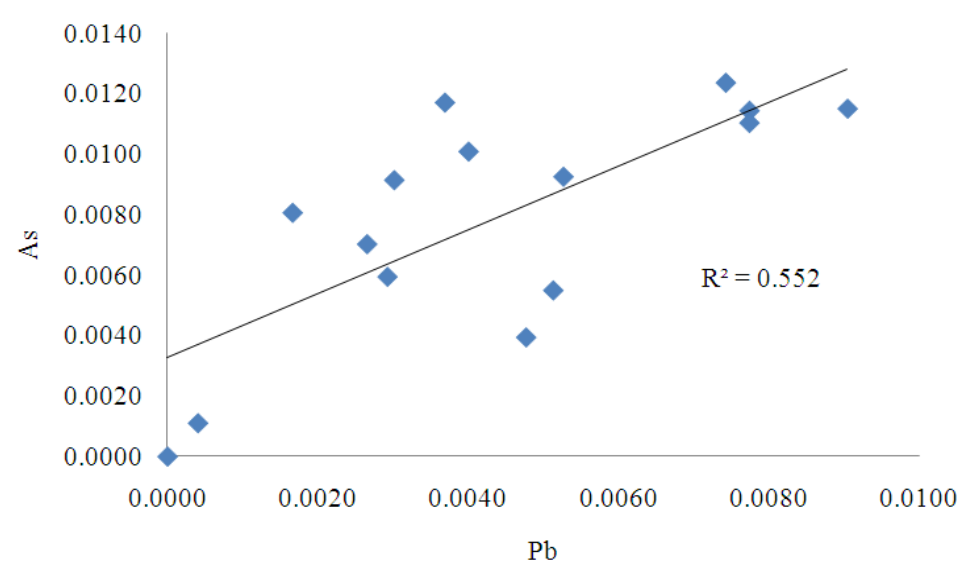

Fig. 3. As concentration as funcation of $\mathrm{Pb}$ cconcentration 


\section{CONCLUSION}

Based on the obtined result of the Elemental analysis of imported canned foods in the city of Riyadh the following conclusion can be drown:

- No contamination have been observed in all samples analyzed

- The essential elements concentration found to be in acceptable level

- The toxic element concentration found to be within the acceptable recommended standard level given by FAO and WHO

- Significant correlation was noted between Se and As

- Positive correlation was noted between Mn and $\mathrm{Ni}$

- Positive correlation was noted between $\mathrm{As}$ and $\mathrm{Pb}$

\section{ACKNOWLEDGMENT}

The auther would like to thank many colleagues at AL imam Mohammad Ibn Saud Islamic University for their valuable help with these experiments.

\section{REFERENCES}

Aliu, S., B. Gashi, I. Rusinovci, S. Fetahu and R. Vataj, 2013. Effects of some heavy metals in some morpho-physiological parameters in maize seedlings. Am. J. Biochem. Biotechnol., 9: 27-33. DOI: 10.3844 /ajbbsp.2013.27.33

Al-Khlaifat, A.L. and O.A. Al-Khashman, 2007. Atmospheric heavy metal pollution in Aqaba city, Jordan, using Phoenix dactylifera L. leaves. Atmospheric Environ., 41: 8891-8897. DOI: 10.1016/j.atmosenv.2007.08.028

CIFA, 1992. Report of the third session of the working party on pollution and fisheries. Committee for Inland Fisheries of Africa.

Das, A., 1990. Metal Ion Induced Toxicity and Detoxification by Chelation Therapy. In: A Text Book on Medical Aspects of Bioinorganic Chemistry, Das, A. (Ed.), CBS, Delhi, pp: 17-58.

FAO/WHO, 1989. Toxicological evaluation of certain food additives and contaminants. WHO Food Additives Series, Cambridge University Press.
Hussein, L. and J. Bruggeman, 1997. Zinc analysis of Egyptian foods and estimated daily intakes among an urban population group. Food Chem., 58: 391398. DOI: 10.1016/S0308-8146(96)00213-0

IOM, 2002. Dietary Reference Intakes for Vitamin A, Vitamin K, Arsenic, Boron, Chromium, Copper, Iodine, Iron, Manganese, Molybdenum, Nickel, Silicon, Vanadium and Zinc. 1st Edn., National Academies Press, Washington, D.C., ISBN-10: 0309072905, pp: 746.

IOM, 2003. Dietary Reference Intakes Applications in Dietary Planning Subcommittee on Interpretation and uses of Dietary Reference Intakesthe Standing Committee on the Scientific Evaluation of Dietary Referenceintakes. 1st Edn., Institute of Medicine Washington, D.C., pp: 248.

Järup, L., 2003. Hazards of heavy metal contamination. Br. Med. Bull., 68:167-82. PMID: 14757716

Joint FAO/WHO, 2011. Report of the fifth session of the codex committee on contaminants in foods. Hague, Netherlands.

Jorherm, L. and B. Sundstroem, 1993. Levels of lead, cadmium, zinc, copper, nickel, chromium, manganese, and cobalt in foods on the swedish market, 1983-1990. J. Food Compos. Anal., 6: 223-241. DOI: 10.1006/jfca.1993.1025

Leblanc, J.C., L. Malmauret, T. Guérin, F. Bordet and B. Boursier et al., 2000. Estimation of the dietary intake of pesticide residues, lead, cadmium, arsenic and radionuclides in France. Food Addit. Contam., 17: 925-932. DOI: 10.1080/026520300750038108

Mani, M., S. Balakrishnan, K. Indira and M. Srinivasan, 2012. Characteristic levels of heavy metals in canned tuna fish. J. Toxicol. Environ. Health Sci., 4: 43-45. DOI: 10.5897/JTEHS11.079

Mohammed, S.G., H.T. Abdulsahib, I.M. Jasim and M.T. Jabbar, 2011. Assessment of camel meat pollution with trace metals in desert area of basra province. Am. J. Agric. Biol. Sci., 6: 475-479. DOI: 10.3844/ajabssp.2011.475.479

Pennington, J., S. Schoen and G. Salmon, 2005. Composition of core foods of the USA food supply 1982-1991. II. Calcium, Magnesium, Iron Emir. J. Agric. Sci., 17: 34-42. 
Tariq, J., M. Jaffar and M. Ashraf, 1993. Heavy metal concentrations in fish, shrimp, seaweed, sediment and water from arabian sea, Pakistan. Marine Poll. Bull., 26: 644-647. DOI: 10.1016/0025326X(93)90504-D

Voegborlo, R.B., A.M.E. Methnani and M.Z. Abedin, 1999. Mercury, cadmium and lead content of canned tunafish. Food Chem., 67: 341-345. DOI: 10.1016/S0308-8146(98)00008-9
Wu Leung, W. and R. Butrum, 1972. Proximate Composition, Mineral and Vitamin Contents of East Asian Foods. In: Food Composition Table for use in East Asia, Wu Leung, W.T., R.R. Butrum, F.N. Chang, N.M. Rao and W. Polacchi, (Eds.), Food and Agriculture Organization, Washington S.N., ISBN-10: 925200159X, pp: 5-187. 